\title{
Progressive Collapse of Multi-Storey Buildings due to Sudden Column Loss - Part I: Simplified Assessment Framework
}

\author{
B.A. Izzuddin ${ }^{1}$, A.G. Vlassis ${ }^{2}$, A.Y. Elghazouli ${ }^{3}$, D.A. Nethercot $^{4}$
}

\begin{abstract}
This paper proposes a novel simplified framework for progressive collapse assessment of multi-storey buildings, considering sudden column loss as a design scenario. The proposed framework offers a practical means for assessing structural robustness at various levels of structural idealisation, and importantly it takes the debate on the factors influencing robustness away from the generalities towards the quantifiable. A major feature of the new approach is its ability to accommodate simplified as well as detailed models of the nonlinear structural response, with the additional benefit of allowing incremental assessment over successive levels of structural idealisation. Three main stages are utilised in the proposed assessment framework, including the determination of the nonlinear static response, dynamic assessment using a novel simplified approach, and ductility assessment. The conceptual clarity of the proposed framework sheds considerable light on the adequacy of commonly advocated measures and indicators of structural robustness, culminating in the proposal of a single rational measure of robustness that is applicable to building structures subject to sudden column loss. The companion paper details the application of the new approach to progressive collapse assessment of real steel-framed composite multi-storey buildings, making in the process important conclusions on the inherent robustness of such structures and the adequacy of current design provisions.
\end{abstract}

Keywords: progressive collapse, robustness, multi-storey buildings, design-oriented method, extreme events, column failure, key vertical element

\footnotetext{
${ }^{1}$ Professor of Computational Structural Mechanics, Dept. Civil \& Env. Eng'g, Imperial College London, SW7 2AZ, (Corresponding author, b.izzuddin@imperial.ac.uk)

${ }^{2}$ Research student, Dept. Civil \& Env. Eng'g, Imperial College London SW7 2AZ

${ }^{3}$ Reader in Engineering Structures, Dept. Civil \& Env. Eng'g, Imperial College London SW7 2AZ

${ }^{4}$ Professor of Civil Engineering, Dept. Civil \& Env. Eng'g, Imperial College London SW7 2AZ
} 


\section{INTRODUCTION}

The events of 11 September 2001 have refocused the efforts of the structural engineering community towards understanding the causes of progressive collapse in building structures, seeking ultimately the establishment of rational methods for the assessment and enhancement of structural robustness under extreme accidental events. Over the past three decades, the UK Building Regulations ${ }^{[1]}$ has led with requirements for the avoidance of disproportionate collapse, which were formulated in the aftermath of the 1968 Ronan Point collapse, and which remain largely unchanged until the present day. These requirements, which are refined in material-specific design codes (e.g. BS5950 ${ }^{[2]}$ for structural steelwork), can be broken down into i) prescriptive 'tying force' provisions which are deemed sufficient for the avoidance of disproportionate collapse, ii) 'notional member removal' provisions which need only be considered if the tying force requirements could not be satisfied, and iii) 'key element' provisions applied to members whose notional removal causes damage exceeding prescribed limits.

It has been recognised that major shortcomings of the current requirements ${ }^{[1,2]}$ are the prescriptive nature of the tying force requirements, deemed sufficient for the avoidance of disproportionate collapse yet unrelated to real structural performance, and the exclusion of ductility considerations ${ }^{[3]}$ at all levels of the provisions. Indeed, the tying force requirements are intended to provide resistance to gravity loading by means of catenary action upon removal of a vertical member, yet the associated ductility demands for specific structural forms can be unrealistically large, thus rendering the provisions unsafe ${ }^{[4]}$. On the other hand, the alternative notional member removal provisions are more performance based, but these are applied with conventional design checks, and hence they ignore the beneficial effects of such nonlinear phenomena as compressive arching and catenary actions. This is turn can lead to the prediction of an unrealistically large damage area exceeding the prescribed limits ${ }^{[1]}$, thus forcing the member to be designed as a key element when this may be unnecessary. A side issue, yet an important one, is that the current requirements ${ }^{[1]}$ allow a substantial amount of local damage due to notional member removal, but they give no guidance on the 
consideration of debris resulting from such damage and its impact on other areas of the building, when this could potentially lead to progressive collapse of the structure.

A further significant shortcoming of the notional member removal provisions ${ }^{[1]}$ is the assumption of a static structural response, when the failure of vertical members under extreme events, such as blast and impact, is a highly dynamic phenomenon. In this respect, sudden column loss represents a more appropriate design scenario, which includes the dynamic influences yet is event-independent. Although such a scenario is not identical in dynamic effect to column damage resulting from impact or blast, it does capture the influence of column failure occurring over a relatively short duration to the response time of the structure. It can also be considered as a standard dynamic test of structural robustness, and may even be applied to various other extreme dynamic events via calibrated design factors. It is therefore unsurprising that sudden column loss is used as the principal design scenario in the two most recent guidelines ${ }^{[5,6]}$ produced in the USA for progressive collapse mitigation.

In this paper, a simplified approach is proposed for progressive collapse assessment of multistorey building structures considering sudden column loss as a design scenario, which offers for the first time a quantitative framework for the consideration of such important issues as ductility, redundancy and energy absorption. The simplicity of the proposed framework is such that it can be directly applied in design practice, and importantly it moves the discussion of structural robustness away from the generalities to the quantifiable, with all the benefits that this brings for understanding and design.

\section{MULTI-LEVEL ASSESSMENT FRAMEWORK}

When a multi-storey building is subjected to sudden column loss, the ensuing structural response is dynamic, typically characterised by significant geometric and material nonlinearity. For steel-framed buildings employing simple or partial-strength connections, the sudden loss of a column (Fig. 1) invariably leads to a considerable concentration of deformations in the connections within the floors above ${ }^{[7]}$, assuming that the remaining columns can take the redistributed gravity load. The failure of these floors on the lower parts of the structure, hence the initiation of progressive collapse, is largely determined by the 
deformation demands on the connections at the maximum dynamic response in relation to their ductility supply. This mode of failure defines a limit state which forms here the basis for quantifying the robustness of multi-storey buildings under sudden column loss scenarios.

The above limit state is evaluated by establishing the maximum dynamic response under gravity loading following sudden column removal, and considering whether the connections have sufficient ductility supply to withstand the associated demands. Although the most accurate approach to establish the former is through nonlinear dynamic finite element analysis, a more practical approach is proposed here which requires only the nonlinear static response, with dynamic effects evaluated in a simplified, yet accurate, manner. Accordingly, the proposed assessment framework utilises three main stages:

i) nonlinear static response of the damaged structure under gravity loading;

ii) simplified dynamic assessment to establish the maximum dynamic response under sudden column loss; and,

iii) ductility assessment of the connections.

The proposed assessment framework may be applied at the overall structural level (Fig. 1) and, importantly, at various sub-structural levels (Fig. 2), according to the required modelling detail and the feasibility of model reduction. In this respect, only the evaluation of the nonlinear static response is affected, with the remaining two stages remaining largely independent of the level of structural idealisation. At the first level of model reduction, consideration may be given to the affected bay of the multi-storey building only (Fig. 2a), with appropriate boundary conditions to represent the interaction with the surrounding structure. Provided the surrounding columns can resist the redistributed load, further model reduction may consider only the floors above the lost column where deformation is concentrated (Fig. 2b). If additionally the affected floors are identical in terms of structure and loading, the axial force in the columns immediately above the lost column becomes negligible, and a reduced model consisting of a single floor system may be considered (Fig. 2c). Finally, ignoring planar effects within the floor slab, individual steel/composite 
beams may be considered at the lowest level of model reduction (Fig. 2d), subject to appropriate proportions of the gravity load.

Even if the relevant conditions of model reduction do not apply, significant benefits can still arise from considering the nonlinear static response at the lower levels of structural idealisation, since this may be used directly to obtain the response at higher levels. For example, the beam models at the lowest level of idealisation (Fig. 2d) can be used to establish the response of a grillage representation of the floor system at the higher level (Fig. 2c), avoiding the need to apportion the gravity load between the beams. Similarly, the individual floor models (Fig. 2c) can be used to assemble the response of the system of affected floors (Fig. 2b) when these are different in terms of structure or loading.

The proposed assessment framework is deterministic, involving the determination of whether the floors above the removed column fail due to excessive dynamic ductility demands. In this context, different column removal scenarios may be considered as separate load cases, similar to conventional structural assessment under typical loading (e.g. gravity, wind). Furthermore, depending on the regularity of the building structure, it may be possible to operate at the lower levels of idealisation (Fig. 2), in which case the number of column removal scenarios can be significantly reduced. However, unlike typical loads where the main source of uncertainty is related to intensity and is reflected in appropriate design load factors, there is no intensity-related uncertainty in sudden column removal. Rather, spatial uncertainty plays a greater role, in the sense that, for example, a ground floor peripheral column has a greater probability of failure due to an external blast than an internal column on the upper floors. This type of uncertainty is not easily reflected in terms of a design factor, though it may be addressed within an overall probabilistic methodology ${ }^{[8]}$, using for its deterministic engine the progressive collapse assessment method proposed here.

The three stages of the proposed multi-level assessment framework are presented in the next sections, followed by the identification of an appropriate measure for building robustness in relation to sudden column removal. 


\section{NONLINEAR STATIC RESPONSE}

Considering the structural system depicted in Fig. 3, the sudden removal of the bottom column (Fig. 3a) is similar in effect to sudden application of the gravity load $\left(\mathrm{P}_{\mathrm{o}}\right)$ on the same structure, particularly when the structure sustains significant deformations as a result. This sudden application of gravity loading leads to dynamic effects, where the ductility demands for all deformation states up to the maximum dynamic response (Fig. 3b) must be met in order to avoid failure. A simplifying feature of the proposed framework is that the maximum dynamic response can be estimated with reasonable accuracy from the nonlinear static response under amplified gravity loading $\left(\lambda_{d} P_{o}\right)$, as illustrated in Fig. $3 c$, thus removing the need for detailed nonlinear dynamic analysis. This bears some similarity to simplified equivalent single-degree-of-freedom (SDOF) models for extreme dynamic loading (e.g. blast), where the deformation modes under static loading are used as a basis for estimating the dynamic response ${ }^{[7,10]}$. Therefore, the nonlinear static response of the structure, excluding the lost column, is required under gravity loading that is varied according to a scaling factor $\left(\mathrm{P}=\lambda \mathrm{P}_{\mathrm{o}}\right)$, where a typical response is shown in Fig. 4 .

\subsection{Detailed Models}

Detailed modelling of the nonlinear static response can be considered at the various levels of structural idealisation (Fig. 2), and this typically involves the use of advanced nonlinear finite elements.

On the beam level (Fig. 2d), detailed modelling allows for geometric and material nonlinearity typically through the use of elasto-plastic beam-column elements ${ }^{[11]}$, and considers the nonlinear connection response most effectively using a component-based method similar to that introduced in EC ${ }^{[12]}$. Detailed modelling on this level has the additional benefit of enabling the realistic representation of composite action between the steel beam and the floor slab, including the influence of partial / full shear connection.

On the floor system level (Fig. 2c), detailed modelling maintains all the aforementioned benefits for individual beams, and further enables a realistic treatment of two-dimensional membrane effects within the floor slab. This is typically achieved using advanced shell 
elements for the slab accounting for geometric and material nonlinearity ${ }^{[13]}$, which are coupled to the beam elements to represent the integrated nonlinear floor response ${ }^{[14]}$.

At the higher levels of structural idealisation (Fig.1, Figs. 2a-b), detailed modelling of the nonlinear static response again maintains the benefits discussed for the lower levels, further providing a realistic representation of the interactions between adjacent subsystems. This may be necessary for irregular building structures, and even for regular buildings with a small number of bays at the boundaries of the damaged bay. In the latter case, significant coupling could arise between the boundary forces and responses at the affected floors, which is difficult to represent by means of equivalent uncoupled boundary springs.

\subsection{Simplified Models}

A major benefit of the proposed assessment framework is that it supports the use of simplified models for determining the nonlinear static response at various levels of structural idealisation. Simplified and detailed models may also be combined, where detailed modelling would be considered at the lower levels of structural idealisation, for example to account accurately for the nonlinear response of individual beams or floors, and simplified modelling would be applied to assemble the nonlinear static response at the higher levels.

\subsubsection{Individual beams}

Simplified models are inherently approximate but can still offer a realistic representation of the nonlinear static response of individual beams (Fig. 2d), provided important characteristics such as the nonlinear connection response and/or tensile catenary action in the presence of axial restraint are modelled. In this direction, explicit simplified models were developed by Izzuddin $^{[15]}$ for application in SDOF blast assessment of steel members, accounting for generalised support conditions and catenary action, and more recently extended to allow for material rate-sensitivity ${ }^{[16]}$.

The potential of simplified modelling was recently demonstrated, where explicit expressions were provided $^{[10]}$ for the elastic, plastic and tensile catenary stages of a simply supported beam with axial end restraints (Fig. 5). These expressions assume a midspan plastic hinge 
occurring in the steel beam, which is applicable in progressive collapse assessment to a double-span beam with a lost internal column, but only when the internal beam-to-column connections are full strength. For partial strength connections, consideration must be given to the elevated centre of rotation of the connection, which can be represented in terms of the idealised plastic interaction between the axial force and moment in the connection, as illustrated in the insets of Fig. 6. Taking $M_{p}$ and $F_{p}$ as the connection plastic moment and axial force capacities, respectively, and assuming the connection to be rigid, alternative simplified expressions are obtained:

$$
\mathrm{P}=\left\{\begin{array}{cc}
76.8 \frac{\mathrm{EI}}{\mathrm{L}^{3}} \mathrm{u}_{\mathrm{s}} & \mathrm{u}_{\mathrm{s}} \leq\left(\mathrm{u}_{\mathrm{s}}^{\mathrm{b}}=\frac{\mathrm{M}_{\mathrm{p}} \mathrm{L}^{2}}{9.6 \mathrm{EI}}\right) \\
\frac{8}{\mathrm{~L}}\left[\mathrm{M}_{\mathrm{p}}+\frac{2 \mathrm{~K}_{\mathrm{e}}}{\mathrm{L}}\left(\mathrm{u}_{\mathrm{s}}-\mathrm{u}_{\mathrm{s}}^{\mathrm{b}}\right) \times \cdots\right. & \mathrm{u}_{\mathrm{s}}^{\mathrm{b}} \leq \mathrm{u}_{\mathrm{s}} \leq\left(\mathrm{u}_{\mathrm{s}}^{\mathrm{d}}=\mathrm{r}_{\mathrm{p}}+\sqrt{\left.\left(\mathrm{r}_{\mathrm{p}}-\mathrm{u}_{\mathrm{s}}^{\mathrm{b}}\right)^{2}+\frac{\mathrm{F}_{\mathrm{p}} \mathrm{L}}{2 \mathrm{~K}_{\mathrm{e}}}\right)}\right. \\
\left.\left(\mathrm{u}_{\mathrm{s}}-\mathrm{r}_{\mathrm{p}}\right)\left(\mathrm{u}_{\mathrm{s}}+\mathrm{u}_{\mathrm{s}}^{\mathrm{b}}-2 \mathrm{r}_{\mathrm{p}}\right)\right] & \\
8 \frac{\mathrm{F}_{\mathrm{p}} \mathrm{u}_{\mathrm{s}}}{\mathrm{L}} & \mathrm{u}_{\mathrm{s}}^{\mathrm{d}} \leq \mathrm{u}_{\mathrm{s}}
\end{array}\right.
$$

where, EA and EI are the beam axial and flexural rigidities for the beam, and $\mathrm{K}_{\mathrm{s}}$ is the support stiffness, with:

$$
r_{p}=\frac{M_{p}}{F_{p}}, \quad K_{e}=\frac{1}{\frac{1}{K_{s}}+\frac{L}{E A}+\frac{1}{K_{s}}}
$$

The response of the beam with a midspan partial strength connection, as expressed by (1), involves a compressive arching stage (Fig. 6), instead of the plastic bending stage, the intensity of which depends on the axial support stiffness. Such arching action is not prominent in typical beam design situations, but it can play an important role in enhancing the nonlinear beam response under column loss scenarios, as demonstrated in the companion $\operatorname{paper}^{[4]}$.

The above simplified beam models are only illustrative, presented here principally to demonstrate the applicability of simplified modelling to geometrically nonlinear phenomena, 
including tensile catenary and compressive arching actions. At present, there is a need for further developments in simplified modelling before it can be applied to progressive collapse assessment in practice, including the realistic representation of the nonlinear response of various connection types as well as composite beams. Such simplified models would be more practical than nonlinear finite element models, and importantly they would be used more consistently. However, in the absence of sufficiently versatile simplified models, detailed models based on nonlinear finite elements remain the most effective means for establishing the large displacement response of individual beams. Indeed, this is the modelling strategy adopted for the case study in the companion paper ${ }^{[4]}$, where detailed modelling is used for individual beams, but this is combined with simplified modelling at the floor level, as discussed next.

\subsubsection{Individual floors}

Simplified modelling can be used to obtain the nonlinear static response of a floor system (Fig. 2c) by assembling the responses of individual beams in a grillage approximation. In this respect, the nonlinear static response of the individual beams may be determined from either detailed or simplified models, as discussed in Sections 3.1 and 3.2.1, respectively. Regardless of the type of model used for an individual beam (i), the nonlinear static response, expressed by the $\left(\mathrm{P}_{\mathrm{i}}, \mathrm{u}_{\mathrm{s}, \mathrm{i}}\right)$ relationship, provides a measure of the energy absorption characteristics of the beam, with the increment of absorbed energy $\left(\delta U_{\mathrm{i}}\right)$ obtained as:

$$
\delta U_{\mathrm{i}}=\alpha_{\mathrm{i}} \mathrm{P}_{\mathrm{i}} \delta \mathrm{u}_{\mathrm{s}, \mathrm{i}}
$$

In this expression, $\alpha_{i}$ is a non-dimensional work-related factor which depends on the assumed load distribution on the beam (e.g. uniformly distributed, point load), but not on the load intensity $\left(\mathrm{P}_{\mathrm{i}}\right)$, and may depend on the incremental deformation mode at the current level of loading. For example, for a point load which directly corresponds to $\mathrm{u}_{\mathrm{s}, \mathrm{i}}$, and for $\mathrm{a}$ uniformly distributed load with an incremental plastic deformation mode as illustrated in Fig. 5 (top-right inset), the values of $\alpha_{i}$ are given by:

$$
\alpha_{i}= \begin{cases}1 & \text { (point load) } \\ 0.5 & \text { (uniformly distributed load) }\end{cases}
$$


When a beam forms part of a grillage approximation for a floor system, the actual load distribution on the beam can be difficult to determine, and it may in fact be changing as the floor system deforms with the loads redistributing between the various beams. However, if the response of an individual beam is dominated by a single mode with discrete hinges, as would be the case when the floor system is subjected to column loss leading to excessive deformations, the incremental energy $\left(\delta U_{i}\right)$ and hence $\left(\alpha_{i} \mathrm{P}_{\mathrm{i}}\right)$ become almost independent of the load distribution on the beam, particularly at large deflections. In this case, the nonlinear static response of the beam may be obtained using an assumed load distribution which does not have to be accurate, even if there could well be some marginal benefit from assuming a distribution that is consistent with rigid-plastic collapse analysis of the whole floor grillage.

On the basis of a dominant deformation mode, as illustrated in Fig. 7, the response of a floor system can be easily assembled from the responses of individual beams by equating the incremental external work and internal absorbed energy:

$$
\delta W=\sum_{\mathrm{i}} \delta U_{\mathrm{i}}
$$

The incremental external work is expressed in terms of the total gravity load supported by the floor system and the incremental deformation as:

$$
\delta W=\alpha \mathrm{P} \delta \mathrm{u}_{\mathrm{s}}
$$

in which $\alpha$ is also a work-related factor that depends on the gravity load distribution, where for uniformly distributed floor loading as shown in Fig. 7:

$$
\alpha=0.25 \text { (uniformly distributed load) }
$$

Considering the system compatibility expressed as a relationship between the component and system deformations:

$$
\mathrm{u}_{\mathrm{s}, \mathrm{i}}=\beta_{\mathrm{i}} \mathrm{u}_{\mathrm{s}}
$$

the combination of (3), (5), (6) and (8) leads to the overall system response:

$$
\mathrm{P}=\frac{1}{\alpha} \sum_{\mathrm{i}} \alpha_{\mathrm{i}} \beta_{\mathrm{i}} \mathrm{P}_{\mathrm{i}}
$$


This provides a direct relationship between $\mathrm{P}$ and $\mathrm{u}_{\mathrm{s}}$ for the floor system, since $\mathrm{P}_{\mathrm{i}}$ for each beam is a function of the corresponding $\mathrm{u}_{\mathrm{s}, \mathrm{i}}$ that is in turn related to $\mathrm{u}_{\mathrm{s}}$ according to (8).

\subsubsection{Multiple floors}

Simplified modelling can also be used to obtain the nonlinear static response of the system of multiple floors above the failed column (Fig. 2b) by assembling the responses of individual floors, each of which may be determined from either detailed or simplified models, as discussed in Sections 3.1 and 3.2.2, respectively. Considering a SDOF deformation mode (Fig. 8) with identical displacements for all floors at the column position:

$$
\mathrm{u}_{\mathrm{s}, \mathrm{j}}=\mathrm{u}_{\mathrm{s}}
$$

the equivalence of internal and external incremental work can again be used to assemble the overall response from individual floor contributions:

$$
P=\frac{1}{\alpha} \sum_{j} \alpha_{j} P_{j}
$$

Here, $\alpha_{j}$ is the work-related factor for floor (j), as given by (7) for uniformly distributed loading. On the other hand, $\alpha$ becomes the overall work-related factor for the whole system, as given for the case of uniformly distributed loading on all floors by:

$$
\alpha=0.25 \text { (uniformly distributed load) }
$$

It is noted that the values of $\left(\alpha_{i}, \alpha_{j}, \alpha\right)$, on the beam, floor and system levels, respectively, may be easily obtained for other load distributions from work considerations, as generically expressed by (6).

\section{SIMPLIFIED DYNAMIC ASSESSMENT}

Under a sudden column loss scenario, a typical building structure exhibits a highly nonlinear dynamic response, and thus any assessment of ductility demands should consider the

maximum dynamic response of the structure. In this respect, the DoD provisions ${ }^{[6]}$ recommend the use of nonlinear dynamic analysis on the damaged structure, though this is overly complicated for practical application in structural design. An alternative simplified 
approach is also allowed by the DoD and GSA guides ${ }^{[5,6]}$, which utilises a static assessment based on a constant dynamic amplification factor $\left(\lambda_{d}=2\right)$ for gravity loading above the damaged column. However, this load amplification is only correct for a linear elastic response, with much smaller amplification factors of between 1.3 and 1.5 established for the nonlinear elasto-plastic response ${ }^{[7]}$.

The emphasis on load amplification in simplified modelling is fraught with difficulties, with the amplification factor depending on both the level of gravity loading and the nature of the nonlinear response. An alternative simplified $\operatorname{approach}^{[17]}$ is instead utilised where the focus is on determining the maximum dynamic response, though the corresponding dynamic load amplification factor $\left(\lambda_{d}\right)$ may also be obtained if required. The essence of this approach is that sudden column loss is similar in effect to sudden application of the gravity load on the affected sub-structure, particularly when significant deformations are sustained as a result. In the initial stages of the dynamic response, the gravity load exceeds the static structural resistance, and the differential work done over the incremental deformations is transformed into additional kinetic energy, thus leading to increasing velocities. As the deformations increase, the static resistance exceeds the gravity loading, and the differential energy absorbed accounts for a reduction in the kinetic energy, thus leading to decreasing velocities. Considering a response dominated by a single deformation mode, the maximum dynamic response is achieved when the kinetic energy is reduced back to zero, and hence when the work done by the gravity loads becomes identical to the energy absorbed by the structure.

The above principle is illustrated in Figs. 9a-b for two levels of suddenly applied gravity loading $\left(\mathrm{P}=\lambda_{1} \mathrm{P}_{\mathrm{o}}, \mathrm{P}=\lambda_{2} \mathrm{P}_{\mathrm{o}}\right)$, where the nonlinear static load-deflection response is employed to determine the corresponding maximum dynamic displacements $\left(u_{d, 1}, u_{d, 2}\right)$. In each case, and with the assumption of a SDOF mode, the equivalence between external work and internal energy is obtained when the two depicted hatched areas become identical. With the availability of the nonlinear static load-deflection response, the level of suddenly applied gravity loading $\left(\mathrm{P}_{\mathrm{n}}=\lambda_{\mathrm{n}} \mathrm{P}_{\mathrm{o}}\right)$ that leads to a specific maximum dynamic displacement $\left(\mathrm{u}_{\mathrm{d}, \mathrm{n}}\right)$ is easily obtained from: 


$$
\begin{aligned}
& W_{\mathrm{n}}=\alpha \lambda_{\mathrm{n}} \mathrm{P}_{\mathrm{o}} \mathrm{u}_{\mathrm{d}, \mathrm{n}} ; \quad U_{\mathrm{n}}=\int_{0}^{\mathrm{u}_{\mathrm{d}, \mathrm{n}}} \alpha \mathrm{Pdu}_{\mathrm{s}} ; \quad W_{\mathrm{n}}=U_{\mathrm{n}} \Rightarrow \\
& \mathrm{P}_{\mathrm{n}}=\lambda_{\mathrm{n}} \mathrm{P}_{\mathrm{o}}=\frac{1}{\mathrm{u}_{\mathrm{d}, \mathrm{n}}} \int_{0}^{\mathrm{u}_{\mathrm{d}, \mathrm{n}}} \mathrm{Pdu_{ \textrm {s } }}
\end{aligned}
$$

where the integral simply represents the area under the nonlinear static $\left(P, u_{s}\right)$ curve for displacements up to $\mathrm{u}_{\mathrm{d}, \mathrm{n}}$. Clearly according to (14), the level of suddenly applied gravity loading $\left(\mathrm{P}_{\mathrm{n}}\right)$ causing a specific maximum dynamic displacement $\left(\mathrm{u}_{\mathrm{d}, \mathrm{n}}\right)$ is identical to the mean static resistance over the displacement range $\left[0, \mathrm{u}_{\mathrm{d}, \mathrm{n}}\right]$.

The application of the proposed simplified approach is considerably simplified if the suddenly applied gravity loading $\left(\mathrm{P}_{\mathrm{n}}\right)$ is plotted against the maximum dynamic displacement $\left(\mathrm{u}_{\mathrm{d}, \mathrm{n}}\right)$, leading to a $\left(\mathrm{P}, \mathrm{u}_{\mathrm{d}}\right)$ curve expressing the maximum nonlinear dynamic response, as depicted in Fig. 9c. This is referred to as the pseudo-static response, since it can be assembled using static analysis principles, as discussed later, while expressing the maximum dynamic response due to suddenly applied loading. With $\mathrm{P}_{\mathrm{o}}$ representing the actual gravity load, the maximum dynamic displacement can be readily obtained from the pseudo-static response at $\left(\mathrm{P}=\mathrm{P}_{\mathrm{o}}\right)$, as illustrated in Fig. 9c, and this can related to the ductility limit considering the deformation demands in the connections, as discussed in Section 5. A simple algorithm for constructing the pseudo-static response curve and establishing the maximum dynamic displacement is provided in Appendix A.

The above simplified dynamic assessment approach, which is verified elsewhere ${ }^{[18]}$, provides clear computational benefits in comparison with detailed nonlinear dynamic analysis, aids in the understanding of the dynamic response characteristics under sudden column loss, and can be easily applied at the various levels of structural idealisation as discussed next.

\subsection{Multi-level Application}

The determination of the nonlinear static response at various levels of structural idealisation is expressed in terms of a corresponding $\left(\mathrm{P}, \mathrm{u}_{\mathrm{s}}\right)$ curve, as illustrated in the context of simplified modelling for individual beams, individual floors and multiple floors in Sections 
3.2.1, 3.2.2 and 3.2.3, respectively. When assessment can be undertaken at a relatively low level of idealisation, such as discussed in Section 2, the maximum dynamic displacement can be obtained directly at this level from the corresponding pseudo-static response $\left(P, u_{d}\right)$ curve using the gravity load $\left(\mathrm{P}_{\mathrm{o}}\right)$ apportioned to the sub-structure under consideration. There is also merit in determining the lower-level pseudo-static response curves, even if the conditions of model reduction are not fulfilled for such levels, and assessment has to be undertaken at a higher level of idealisation. This is particularly useful in simplified modelling where the highlevel response is assembled from the lower-level responses, as discussed for example in Sections 3.2.2 and 3.2.3, in which case the pseudo-static response may be assembled identically to the nonlinear static response, as verified in Appendix B.

Of course, the determination of the pseudo-static response at the assessment level from the assembled nonlinear static response is more efficient than its assembly from the pseudo-static responses at the lower-levels, since it avoids applying (14) or the related algorithm in Appendix A for all the lower-level sub-systems. However, the latter approach is still beneficial in that it sheds light on the relative pseudo-static contributions from the lower-level sub-systems, and it facilitates the consideration of 'what if' scenarios at various levels of idealisation while readily accounting for the sudden nature of applied loading.

\section{DUCTILITY ASSESSMENT}

This is the final stage of assessment where the maximum dynamic displacement $\left(u_{d}\right)$ under the applied gravity loading $\left(\mathrm{P}=\mathrm{P}_{\mathrm{o}}\right)$ is compared to the ductility limit $\left(\mathrm{u}_{\mathrm{f}}\right)$ to establish the limit state. Alternatively, the limit state may be established by comparing $\mathrm{P}_{\mathrm{o}}$ to the pseudostatic capacity $\left(\mathrm{P}_{\mathrm{f}}\right)$, defined as the maximum value of $\mathrm{P}$ for which the resulting $\mathrm{u}_{\mathrm{d}}$ is less or equal to $u_{f}$. It is noted that $P_{f}$ typically corresponds to $u_{f}$ on the pseudo-static response curve, unless this response is characterised by softening such as due to compressive arching.

In determining the ductility limit, the variation of connection deformation demands with $u_{d}$ is considered, and $u_{f}$ is established as the minimum value of $u_{d}$ for which the deformation demand exceeds the supply in any of the connections. When the response at the system assessment level is obtained from simplified assembly of lower-level models, the 
displacements of the sub-systems can be determined from $u_{d}$ using the relevant compatibility conditions. The connection deformations are then determined from the displacements at the lowest level of considered sub-system, whether represented by detailed beam/floor models or by simplified beam models, as described in Sections 3.1 and 3.2.1 respectively. Typically for the former detailed models, the correlation between connection deformations and sub-system displacements is obtained from the numerical simulation of the nonlinear static response, whereas for the latter simplified models such correlation may be analytical. In any case, it is important that both rotational and axial connection deformations are considered, the latter being especially significant in the presence of sufficient axial restraint leading to catenary action.

Once the connection deformations have been established, these can be transformed into ductility demands in various components of the connection, which can thus be compared to ductility supply, as demonstrated for a range of connection types in the companion paper ${ }^{[4]}$. It is noted that there is currently a shortage of data on connection ductility supply, especially in relation to the combined influence of rotational and axial connection deformations, and more so for connections that are not considered within the context of seismic design. Available resources, both codified and research-related, are highlighted in the companion paper ${ }^{[4]}$ for simple and partial-strength connections, though there is still a considerable need for extensive experimental work to determine the ductility supply of various connection types under general deformation conditions. The assessment framework proposed here could readily employ such accurate data on connection ductility supply as and when it becomes available, thus providing the means for evaluating with more certainty the floor failure limit state and, accordingly, the potential for progressive collapse.

The system limit state is defined above by the failure of a single connection, with the ductility demand exceeding the ductility supply in one or more of the connection components. In the more general case, where the failure of a relatively non-ductile connection may not lead to system failure, such as when the system has sufficient residual redundancy and ductility, the 
limit state may be re-evaluated for the system excluding the failed connection and any affected sub-systems beyond the associated ductility limit.

\section{MEASURES OF ROBUSTNESS}

Adequate tying force capacity ${ }^{[1]}$ has long been adopted in design codes ${ }^{[2]}$ and considered as a means of enhancing, if not measuring, structural robustness. Other factors, such as i) energy absorption capacity (or toughness), ii) ductility supply, and iii) redundancy (or alternate load paths), have also been considered as indicators of structural robustness. However, the absence of a coherent system-level assessment framework that accounts for such factors has kept the debate regarding structural robustness in the realm of generalities.

The proposed multi-level framework provides for the first time the means for assessing the robustness of building structures, considering in this instance sudden column loss scenarios. This intuitive framework deals with long-standing questions on the significance of energy absorption, ductility and redundancy as indicators of structural robustness, and considers the interaction between such factors at the system and sub-system levels.

Commonly advocated measures of robustness are considered hereafter, culminating in the proposal of a single all-encompassing measure that is applicable to sudden column loss.

\subsection{Energy Absorption Capacity}

The energy absorption capacity of vehicles is commonly considered as a principal measure of their crashworthiness. The idea of energy absorption capacity as a measure of building robustness is therefore attractive, but it suffers from a fundamental flaw in that energy demand is not only a function of the event but also of the structural response.

According to Section 4, the energy absorbed by a building structure under sudden column loss is proportional to its pseudo-static resistance and dynamic displacement. When the pseudo-static resistance is monotonically increasing with displacement, the energy absorption capacity is obtained from the pseudo-static capacity and the ductility limit as:

$$
U_{\mathrm{f}}=\alpha \mathrm{P}_{\mathrm{f}} \mathrm{u}_{\mathrm{f}}
$$


As illustrated in Fig. 10, it is clear that different pseudo-static responses with an identical energy absorption capacity are not equally adequate to resist the same suddenly applied load $\left(\mathrm{P}_{\mathrm{o}}\right)$. Therefore, the energy absorption capacity cannot be used as a single measure of structural robustness, whether for sudden column loss scenarios or other scenarios associated with gravity-induced limit states.

The generally acknowledged benefit of increased energy absorption still applies for structures subject to sudden column loss, provided this is accompanied by an increased pseudo-static capacity. Considering the pseudo-static softening response in Fig. 11, which could be due to compressive arching action, an increased ductility limit for the depicted range of displacement beyond $\mathrm{u}_{\mathrm{d}, \mathrm{p}}$ leads to an increased energy absorption capacity but not to an increased pseudo-static capacity, and is therefore not beneficial for robustness under sudden column loss scenarios.

\subsection{Redundancy}

Redundancy, or alternative load paths, is a characteristic that is often advocated as beneficial for structural robustness. Such benefits are guaranteed in conventional strength-based plastic design, where the plastic strength of components is typically achieved at relatively small displacements. However, the same benefits cannot be guaranteed in progressive collapse assessment, where reliance is placed on the ultimate strength, which is difficult to achieve simultaneously for all components before a ductility limit is reached.

The above point is illustrated in Fig. 12 with reference to determinant and redundant floor system configurations, the former consisting of two uncoupled beams, while the latter incorporates redundancy from a rigid transverse beam with a pinned joint. When the outer beam has significant pseudo-static capacity in the determinant configuration, the introduced redundancy improves the system pseudo-static capacity (Fig. 12a) in a manner similar to conventional strength-based plastic design. On the other hand, when the outer beam is already at or close to its pseudo-static capacity, the same redundancy reduces the system pseudo-static capacity (Fig. 12b), since the inner beam can only realise a fraction of its pseudo-static capacity at failure of the outer beam. 


\subsection{Ductility Supply}

As discussed previously, improved ductility supply for a structural system subject to sudden loading is only beneficial if it increases the pseudo-static resistance, with the system ductility supply typically determined by a critical component according to deformation compatibility. While on the system level the pseudo-static capacity should be maximised even at the cost of reduced system ductility, this objective should not be generalised to the sub-system levels, particularly for redundant systems. This is because the ductility of a critical sub-system plays a paramount role in realising the overall system pseudo-static capacity.

In designing a sub-system/component which forms part of a redundant system, a useful parameter is the optimal ductility of the sub-system, which is defined as the ductility demand on the sub-system at the point of realising the maximum contribution to the system pseudostatic capacity from the remaining sub-systems, accounting for their ductility supply. A subsystem is critical if its ductility supply is less or equal to its optimal ductility, in which case it determines the ductility supply of the overall system. When considering a critical sub-system, an improved system pseudo-static capacity can be achieved by increasing the sub-system pseudo-static capacity and/or ductility supply. For a non-critical sub-system the system pseudo-static capacity can be improved by increasing the pseudo-static resistance of the subsystem at its optimal ductility demand, but simply varying the sub-system ductility supply above the optimal ductility has no influence.

Some of the above points are illustrated with reference to the redundant grillage floor system of Fig. 12, where consideration is given to the design of the transverse beam connection, previously assumed to be pinned. When the influence of redundancy is positive (Fig. 12a), further improvement of the system pseudo-static capacity can be achieved by maximising the pseudo-static resistance of the connection at its optimal ductility, determined from the demand at the depicted maximum deformed configuration. If the ductility supply of the connection is less than its optimal ductility, it becomes the critical component, and the overall system pseudo-static capacity may be reduced below the value of the original pinned case if the connection pseudo-static capacity is relatively small. Similar criteria apply when the 
influence of redundancy is negative (Fig. 12b), though consideration may be given in this case to selecting a connection such that its pseudo-static resistance more than compensates for the negative influence of redundancy. If this is not possible, and the pseudo-static capacity of the uncoupled beams is adequate for the applied loading, the connection may be designed as a fuse, enabling the early disconnection of the transverse beam from its support. In this case, the connection ductility supply would have to be much less than its optimal ductility, such a case offering a clear example of an arrangement for which increased component ductility may in fact be detrimental.

\subsection{Proposed Measure of Robustness}

In the light of the above discussion, it is evident that commonly advocated indicators are inadequate on their own as measures of structural robustness, particularly since all of these can have positive as well as negative influences. For sudden column loss scenarios, it is proposed that the single measure of structural robustness is the system pseudo-static capacity $\left(\mathrm{P}_{\mathrm{f}}\right)$, the comparison of which against the applied gravity loading $\left(\mathrm{P}_{\mathrm{o}}\right)$ establishes the required limit state. The multi-level approach proposed in this work offers the first coherent framework for determining this system pseudo-static capacity, accounting for the resistance, ductility supply and energy absorption capacity of the various sub-systems, and dealing with redundancy and the interaction of such sub-systems within the overall structural system.

\section{CONCLUSION}

This paper proposes a multi-level framework for progressive collapse assessment of building structures subject to sudden column loss, which benefits from practical applicability and moves the debate surrounding structural robustness towards the quantifiable. The proposed method can accommodate simplified as well as detailed models of the nonlinear structural response, where detailed and simplified modelling approaches may even be combined to provide the most effective representation for the considered level of structural idealisation. The proposed assessment framework employs three stages, namely i) determination of the nonlinear static response, ii) simplified dynamic assessment, and iii) ductility assessment, which are discussed in detail. 
Benefiting from the conceptual clarity of the new framework, it is shown that previously advocated indicators, including the energy absorption capacity, redundancy and ductility, are not individually suitable as measures of structural robustness. However, the system pseudostatic capacity, encompassing the three aforementioned indicators, is identified as a new and rational measure of building robustness under sudden column loss scenarios.

The proposed framework offers a rational system-level approach for assessing the potential of a building structure to collapse under sudden column loss, and could in due course replace the 'tying force' requirements and the 'notional member removal' provisions currently employed in current design codes.

The companion paper demonstrates the application of the proposed progressive collapse assessment framework to steel-framed composite buildings with simple/partial-strength connections, making in the process important conclusions relating to the inherent robustness of such structures, the factors influencing this robustness, and the adequacy of current regulations for the avoidance of disproportionate collapse.

\section{ACKNOWLEDGMENT}

The authors would like to acknowledge the financial support provided for this work by ARUP and EPSRC under a Case award scheme. The significant input into this project of several ARUP staff, especially Faith Wainwright, Mike Banfi and Michael Willford, is also gratefully acknowledged. 


\section{REFERENCES}

1. Office of the Deputy Prime Minister (2004), The Building Regulations 2000, Part A, Schedule 1: A3, Disproportionate Collapse, London, UK.

2. British Standards Institution (2001), BS 5950: Structural Use of Steelwork in Buildings, Part 1: Code of Practice for Design - Rolled and Welded Sections, London, UK.

3. Ove Arup \& Partners Ltd (2003), A Scoping Study - The Building Regulations: Post September 11, Office of the Deputy Prime Minister, London, U.K.

4. Vlassis, A.G., Izzuddin, B.A., Elghazouli, A.Y., and Nethercot, D.A. (2006), "Progressive Collapse of Multi-Storey Buildings due to Sudden Column Loss - Part II: Application”, (Companion Paper).

5. General Services Administration (2003), Progressive Collapse Analysis and Design Guidelines for New Federal Office Buildings and Major Modernization Projects, Washington, DC, USA.

6. Department of Defense (2005), Unified Facilities Criteria, Design of Buildings to Resist Progressive Collapse, UFC 4-023-03, Washington, DC, USA.

7. Marchand, K.A., and Alfawakhiri, F. (2004), "Blast and Progressive Collapse", Facts for Steel Buildings, No. 2, AISC, USA.

8. Ellingwood, B.R., Smilowitz, R., Dusenberry, D.O., Duthinh, D., Lew, H.S., and Carino, N.J. (2007), "Best Practices for Reducing the Potential for Progressive Collapse in Buildings", National Institute of Standards and Technology, NISTIR 7396, USA.

9. Biggs, J.M. (1964), Introduction to Structural Dynamics, McGraw Hill.

10. Izzuddin, B.A. (2005), “A Simplified Model for Axially Restrained Beams Subject to Extreme Loading”, International Journal of Steel Structures, Vol. 5, pp. 421-429.

11. Izzuddin, B.A., and Elnashai, A.S. (1993), "Adaptive Space Frame Analysis - Part II: Distributed Plasticity Approach", Structures and Buildings, Proceedings of the Institution of Civil Engineers, Vol. 99, pp. 317-326.

12. European Committee for Standardization (2005), EN 1993-1-8:2003, Eurocode 3: Design of Steel Structures - Part 1-8: Design of Joints, Brussels. 
13. Izzuddin, B.A., Tao, X.Y., and Elghazouli, A.Y. (2004), "Realistic Modelling of Composite and Reinforced Concrete Floor Slabs under Extreme Loading. Part I: Analytical Method”, Journal of Structural Engineering, ASCE, Vol. 130, No. 12, pp. 1972-1984.

14. Izzuddin, B.A. (2003), "Integration of Beam-Column and Shell Elements in Large Displacement Structural Analysis", Proceedings of the International Symposium on New Perspectives for Shell and Spatial Structures, IASS-APCS 2003, Taipei, Taiwan.

15. FABIG, Technical Note 7 (2002). An Improved SDOF Model for Steel Members Subject to Explosion Loading - Generalised Supports and Catenary Action, The Steel Construction Institute.

16. FABIG, Technical Note 10 (2007). An Advanced SDOF Model for Steel Members Subject to Explosion Loading - Material Rate Sensitivity, The Steel Construction Institute.

17. Izzuddin, B.A. (2004), Ductility Assessment for an Idealized Elasto-Plastic Structural System Subject to an Instantaneous Applied Load, Internal discussion document, Imperial College London, U.K.

18. Vlassis, A.G. (2007), Progressive Collapse Assessment of Tall Buildings, $\mathrm{PhD}$ Thesis, Imperial College London, U.K.. 


\section{APPENDIX A: PSEUDO-STATIC RESPONSE}

Assuming a nonlinear static response defined in terms of a $\left(\mathrm{P}, \mathrm{u}_{\mathrm{s}}\right)$ curve, the following algorithm can be used to construct the pseudo-static response $\left(\mathrm{P}, \mathrm{u}_{\mathrm{d}}\right)$ curve and to establish the dynamic displacement corresponding to full suddenly applied gravity loading $\left(\mathrm{P}=\mathrm{P}_{\mathrm{o}}\right)$. In this algorithm, and with reference to Fig. $9, \mathrm{P}_{\mathrm{m} \backslash \mathrm{n}}$ refers to the suddenly applied load $\left(\lambda_{\mathrm{m} \backslash \mathrm{n}} \mathrm{P}_{\mathrm{o}}\right)$, while $\mathrm{P}_{\mathrm{d}, \mathrm{m} \backslash \mathrm{n}}$ refers to the amplified static load $\left(\lambda_{\mathrm{d}, \mathrm{m} \backslash \mathrm{n}} \mathrm{P}_{\mathrm{o}}\right)$, with $\mathrm{m}$ and $\mathrm{n}$ indicating the start and end of the current increment, respectively.

1. Initialise: $\mathrm{P}_{\mathrm{d}, \mathrm{m}}=\mathrm{P}_{\mathrm{m}}=0, \mathrm{u}_{\mathrm{d}, \mathrm{m}}=0, \mathrm{~A}_{\mathrm{m}}=0$;

choose a small displacement increment $\Delta \mathrm{u}_{\mathrm{d}}$

2. Set: $\mathrm{u}_{\mathrm{d}, \mathrm{n}}=\mathrm{u}_{\mathrm{d}, \mathrm{m}}+\Delta \mathrm{u}_{\mathrm{d}}$

3. Determine $\mathrm{P}_{\mathrm{d}, \mathrm{n}}$ corresponding to $\mathrm{u}_{\mathrm{d}, \mathrm{n}}$ from nonlinear static response $\left(\mathrm{P}, \mathrm{u}_{\mathrm{s}}\right)$ curve;

obtain current area under the $\left(P, \mathrm{u}_{\mathrm{s}}\right)$ curve: $\mathrm{A}_{\mathrm{n}}=\mathrm{A}_{\mathrm{m}}+\left(\mathrm{P}_{\mathrm{d}, \mathrm{m}}+\mathrm{P}_{\mathrm{d}, \mathrm{n}}\right) \Delta \mathrm{u}_{\mathrm{d}} / 2$

4. Determine current pseudo-static load: $\mathrm{P}_{\mathrm{n}}=\mathrm{A}_{\mathrm{n}} / \mathrm{u}_{\mathrm{d}, \mathrm{n}}$;

establish new point $\left(P_{n}, u_{d, n}\right)$ on pseudo-static response $\left(P, u_{d}\right)$ curve

5. If ( $\left.\mathrm{P}_{\mathrm{m}}<\mathrm{P}_{\mathrm{o}} \leq \mathrm{P}_{\mathrm{n}}\right)$, obtain and output dynamic displacement corresponding to $\mathrm{P}_{\mathrm{o}}$ :

$\mathrm{u}_{\mathrm{d}}=\mathrm{u}_{\mathrm{d}, \mathrm{m}}+\left(\mathrm{u}_{\mathrm{d}, \mathrm{n}}-\mathrm{u}_{\mathrm{d}, \mathrm{m}}\right)\left(\mathrm{P}_{\mathrm{o}}-\mathrm{P}_{\mathrm{m}}\right) /\left(\mathrm{P}_{\mathrm{n}}-\mathrm{P}_{\mathrm{m}}\right)$

6. If more points are required for pseudo-static response curve:

update: $\mathrm{P}_{\mathrm{d}, \mathrm{m}}=\mathrm{P}_{\mathrm{d}, \mathrm{n}}, \mathrm{P}_{\mathrm{m}}=\mathrm{P}_{\mathrm{n}}, \mathrm{u}_{\mathrm{d}, \mathrm{m}}=\mathrm{u}_{\mathrm{d}, \mathrm{n}}, \mathrm{A}_{\mathrm{m}}=\mathrm{A}_{\mathrm{n}}$;

repeat from step 2. 


\section{APPENDIX B: SIMPLIFIED PSEUDO-STATIC ASSEMBLY}

Consider the general form of assembling the system nonlinear static resistance from that of lower-level sub-systems according to:

$$
\mathrm{P}=\frac{1}{\alpha} \sum_{\mathrm{i}} \alpha_{\mathrm{i}} \beta_{\mathrm{i}} \mathrm{P}_{\mathrm{i}}
$$

where $\mathrm{P}$ and $\mathrm{P}_{\mathrm{i}}$ are respectively dependent on $\mathrm{u}_{\mathrm{s}}$ and $\mathrm{u}_{\mathrm{s}, \mathrm{i}}$ that are related by:

$$
\mathrm{u}_{\mathrm{s}, \mathrm{i}}=\beta_{\mathrm{i}} \mathrm{u}_{\mathrm{s}}
$$

The pseudo-static resistance for the system is obtained according to (14), leading to:

$$
P_{n}=\frac{1}{u_{d, n}} \int_{0}^{u_{d, n}} P d u_{s}=\frac{1}{\alpha} \sum_{i} \frac{\alpha_{i} \beta_{i}}{u_{d, n}} \int_{0}^{u_{d, n}} P_{i} d u_{s}
$$

The integral for each sub-system (i) can be expressed over the corresponding displacement as:

$$
\frac{1}{u_{d, n}} \int_{0}^{u_{d, n}} P_{i} d u_{s}=\frac{1}{\beta_{i} u_{d, n}} \int_{0}^{\beta_{i} u_{d, n}} P_{i} d\left(\beta_{i} u_{s}\right)=\frac{1}{u_{d, n, i}} \int_{0}^{u_{d, n, i}} P_{i} d u_{s, i}=P_{n, i}
$$

Therefore, considering (18) and (19), the pseudo-static responses at the system and subsystem levels are identically related to the static response:

$$
\mathrm{P}_{\mathrm{n}}=\frac{1}{\alpha} \sum_{\mathrm{i}} \alpha_{\mathrm{i}} \beta_{\mathrm{i}} \mathrm{P}_{\mathrm{n}, \mathrm{i}}
$$

where $\mathrm{P}_{\mathrm{n}}$ and $\mathrm{P}_{\mathrm{n}, \mathrm{i}}$ are respectively dependent on $\mathrm{u}_{\mathrm{d}, \mathrm{n}}$ and $\mathrm{u}_{\mathrm{d}, \mathrm{n}, \mathrm{i}}$ that are also related by the same compatibility conditions used for assembling the static response:

$$
\mathrm{u}_{\mathrm{d}, \mathrm{n}, \mathrm{i}}=\beta_{\mathrm{i}} \mathrm{u}_{\mathrm{d}, \mathrm{n}}
$$


Figure 1. Multi-storey building subject to sudden column loss

Figure 2. Sub-structural levels for progressive collapse assessment

Figure 3. Sudden column removal modelled using amplified static loading

Figure 4. Characteristic nonlinear static response

Figure 5. Simplified beam model with tensile catenary action (Izzuddin, 2005)

Figure 6. Simplified beam model with compressive arching and tensile catenary actions

Figure 7. Grillage approximation of a floor system with three beams

Figure 8. Simplified model for multiple floor system consisting of three floors

Figure 9. Simplified dynamic assessment and definition of pseudo-static response

Figure 10. Different pseudo-static responses with identical energy absorption capacity

Figure 11. Significance of increased energy absorption capacity

Figure 12. Influences of redundancy in progressive collapse assessment 


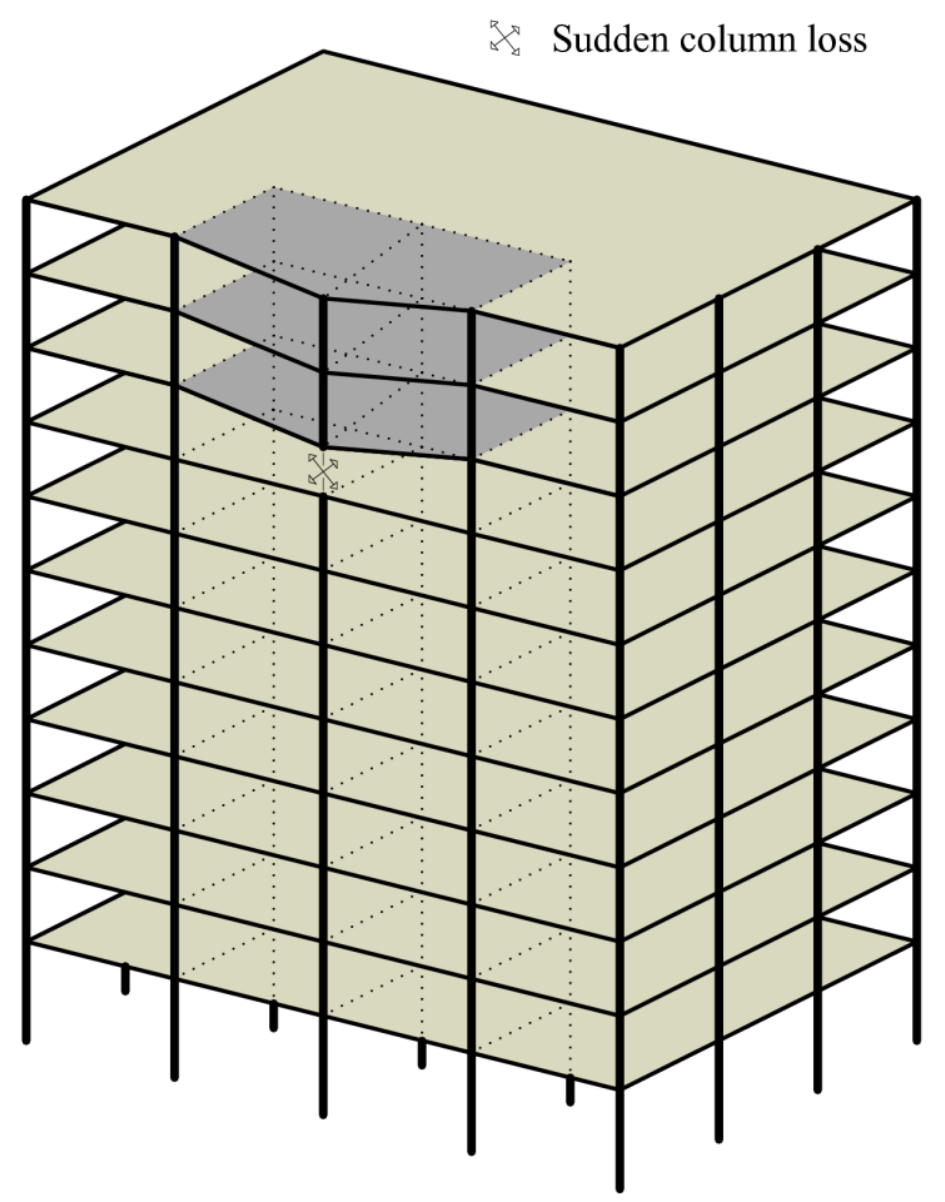

Figure 1. Multi-storey building subject to sudden column loss 
Sudden column loss

M Translational/rotational springs
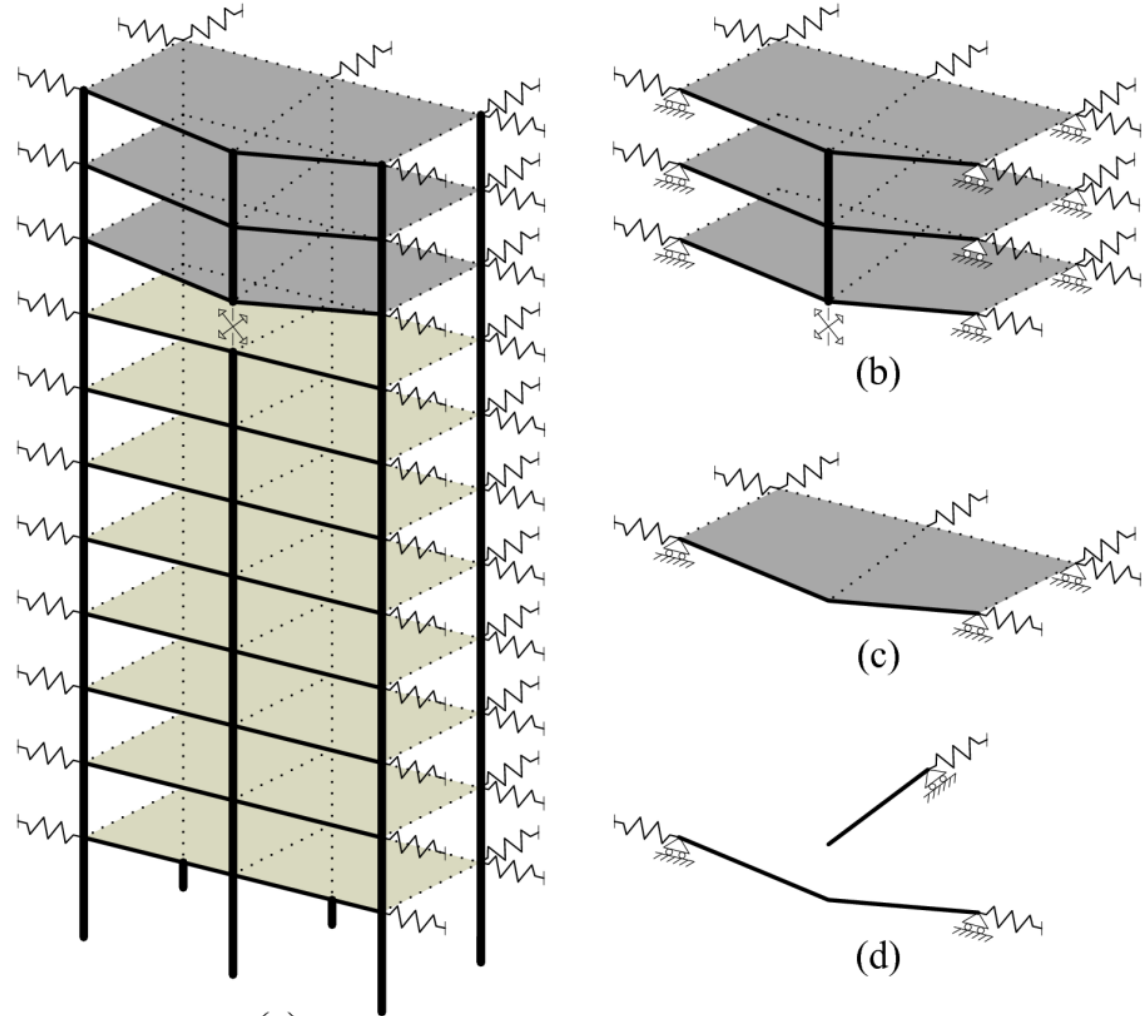

(b)

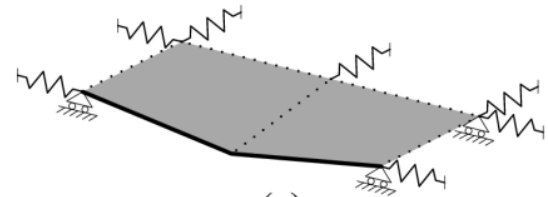

(c)

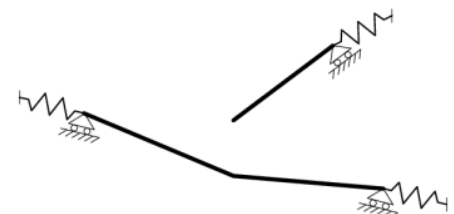

(d)

(a)

Figure 2. Sub-structural levels for progressive collapse assessment 


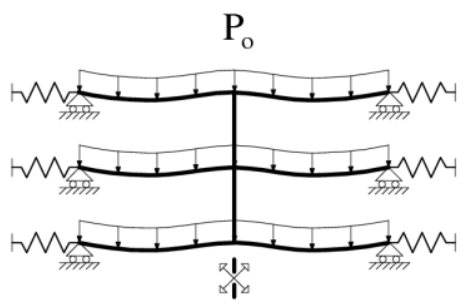

(a) Sudden column loss

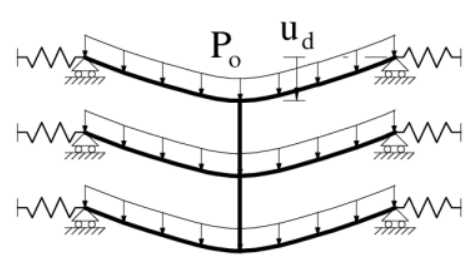

(b) Maximum dynamic response

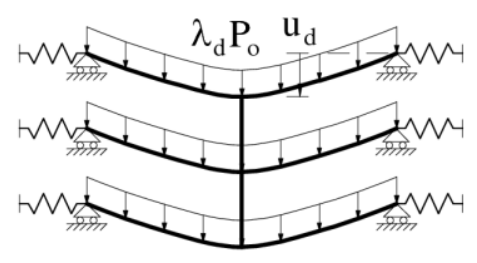

(c) Amplified static loading

Figure 3. Sudden column removal modelled using amplified static loading 


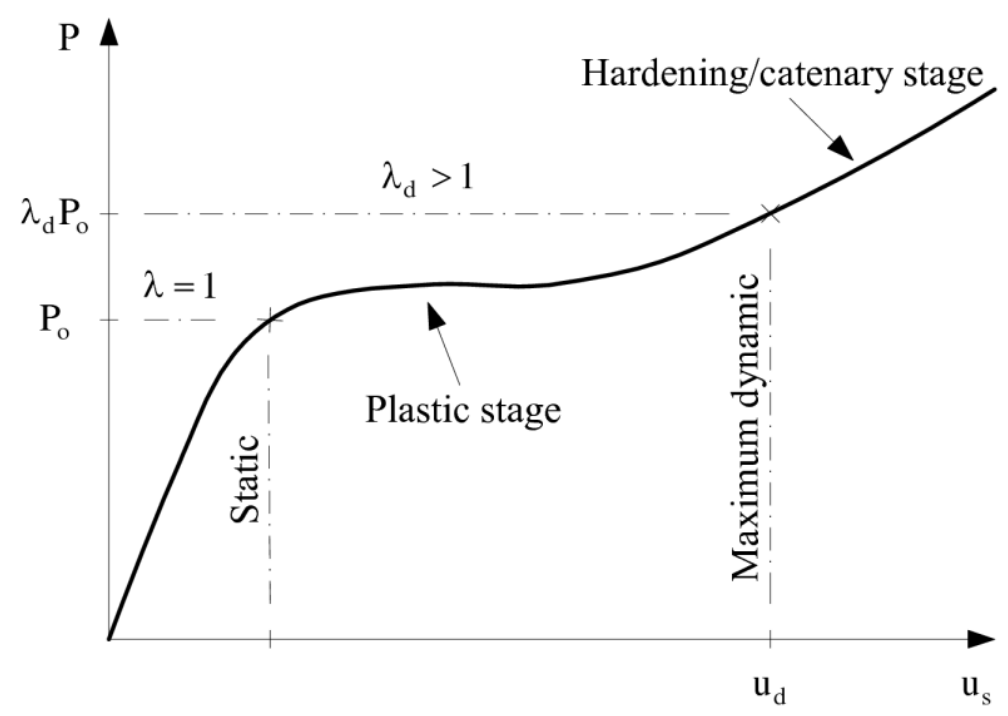

Figure 4. Characteristic nonlinear static response under proportional load $\left(P=\lambda P_{0}\right)$ 

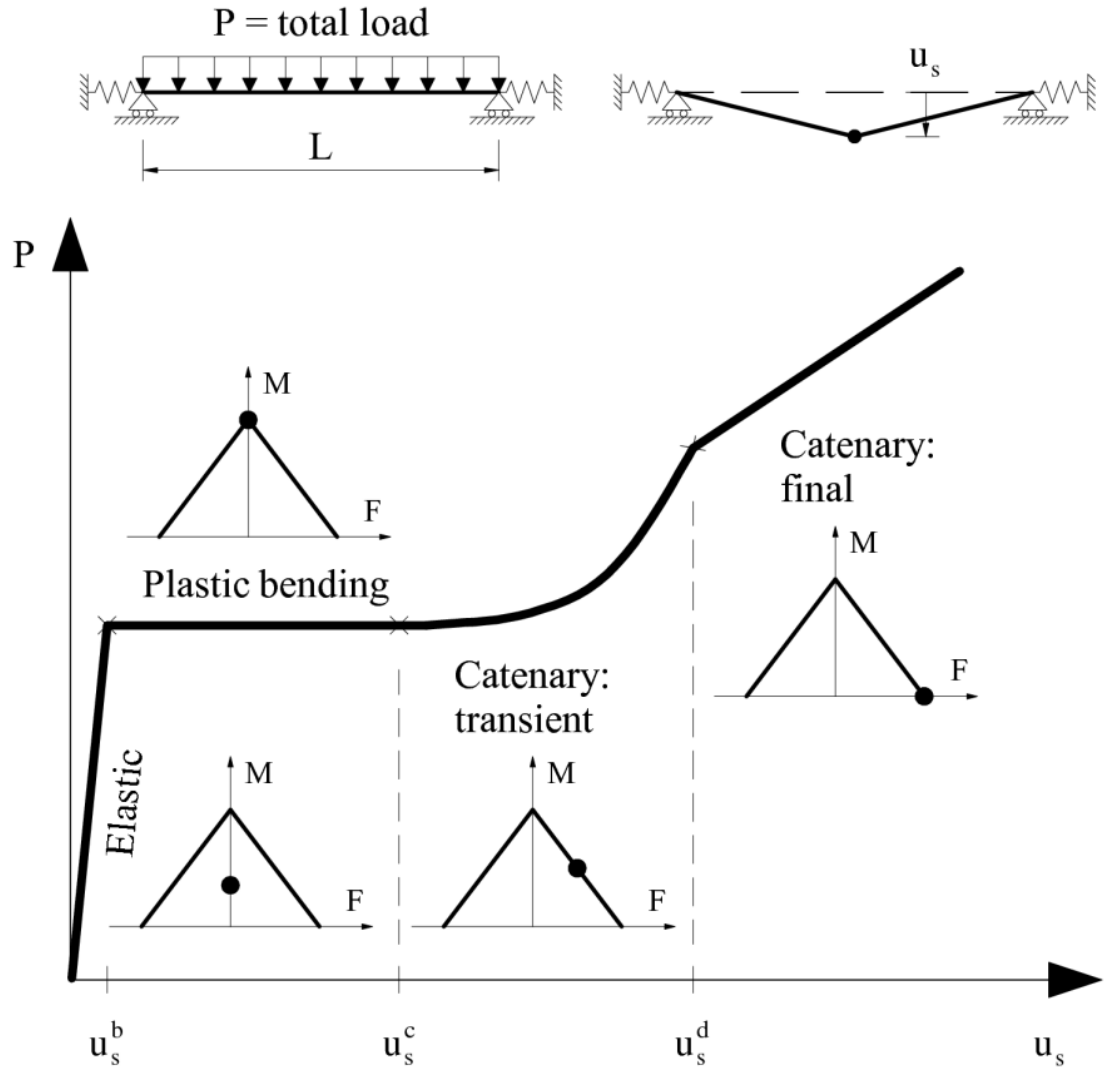

Figure 5. Simplified beam model with tensile catenary action (Izzuddin, 2005) 


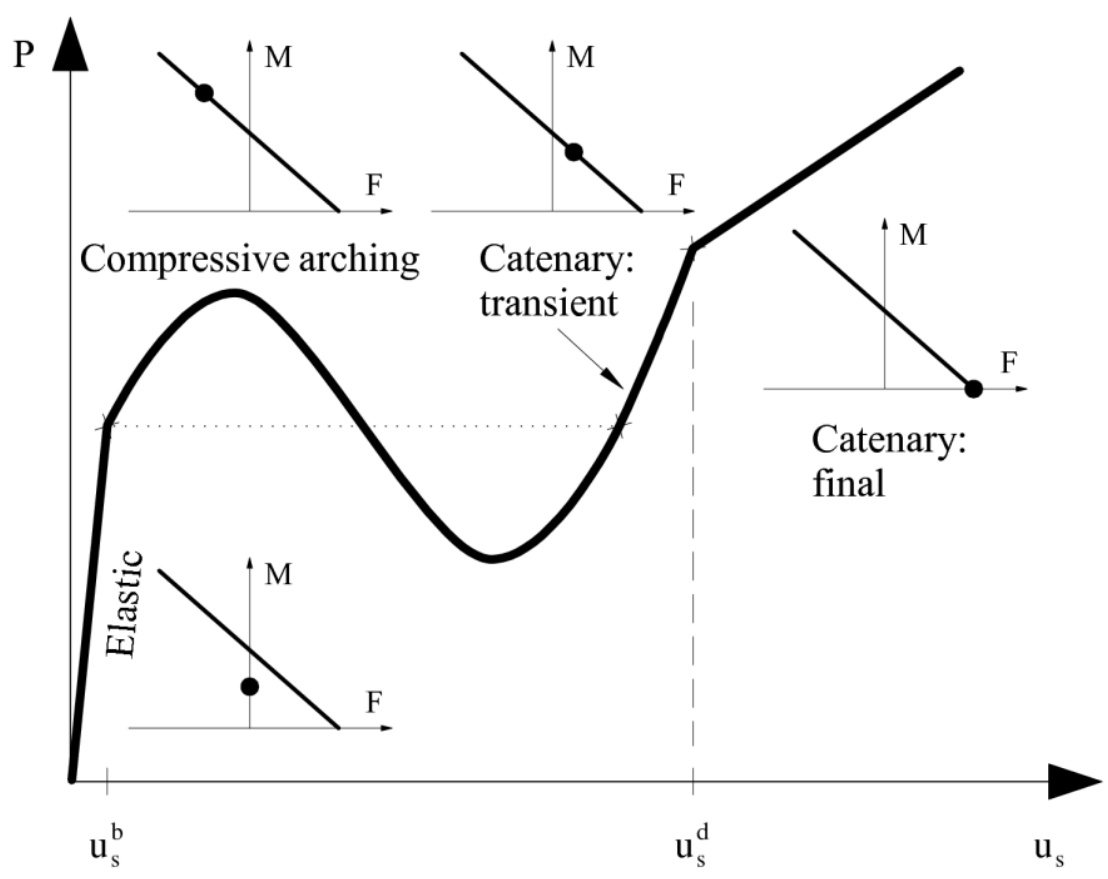

Figure 6. Simplified beam model with compressive arching and tensile catenary actions 


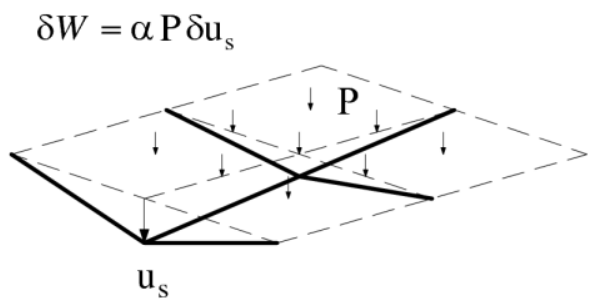

Dominant mode for floor system

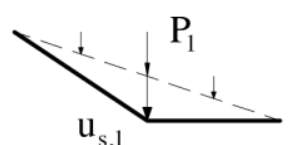

$\mathrm{u}_{\mathrm{s}, 1}=\beta_{1} \mathrm{u}_{\mathrm{s}}$ $\delta U_{1}=\alpha_{1} \mathrm{P}_{1} \delta \mathrm{u}_{\mathrm{s}, 1}$

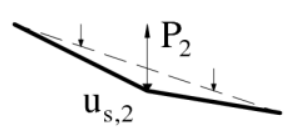

$\mathrm{u}_{\mathrm{s}, 2}=\beta_{2} \mathrm{u}_{\mathrm{s}}$ $\delta U_{2}=\alpha_{2} \mathrm{P}_{2} \delta \mathrm{u}_{\mathrm{s}, 2}$

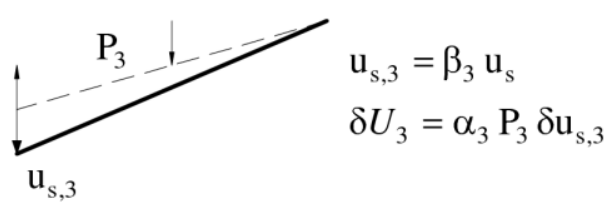

Individual beam modes

Figure 7. Grillage approximation of a floor system with three beams 


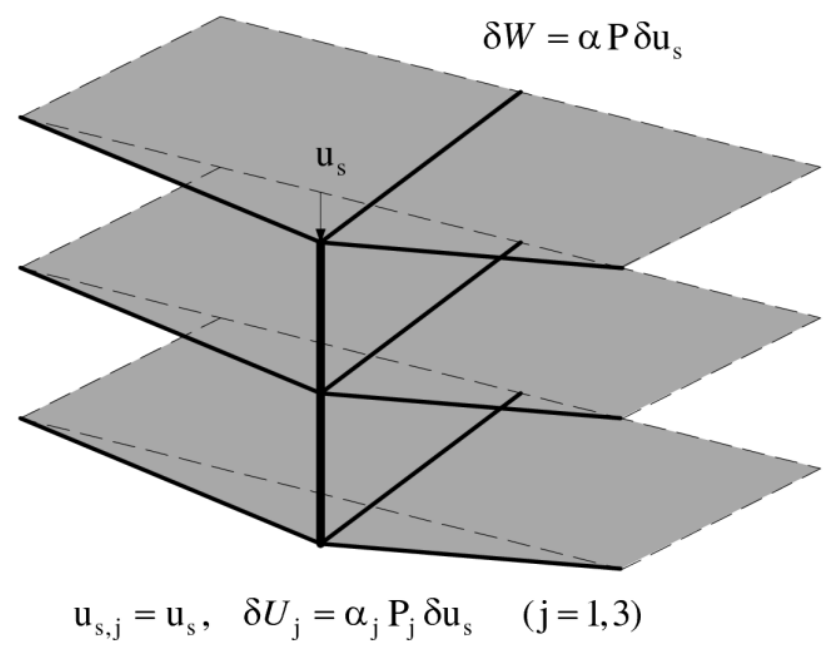

Figure 8. Simplified model for multiple floor system consisting of three floors 


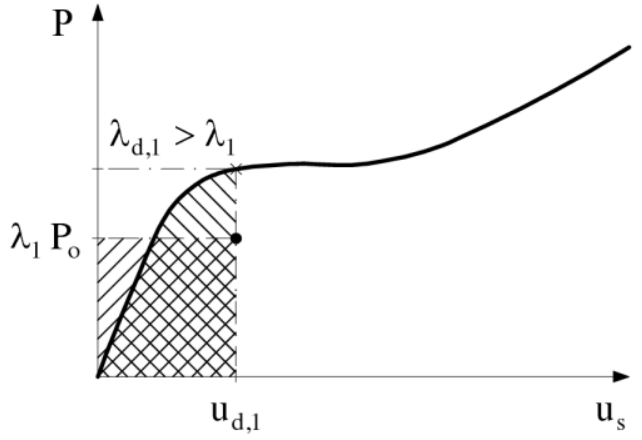

(a) Dynamic response $\left(\mathrm{P}=\lambda_{1} \mathrm{P}_{\mathrm{o}}\right)$

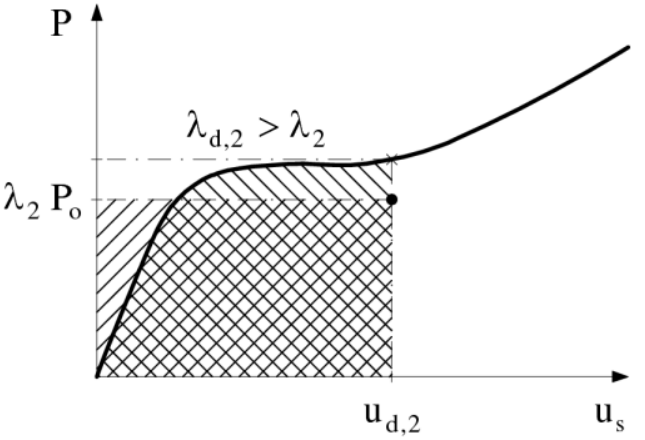

(b) Dynamic response $\left(\mathrm{P}=\lambda_{2} \mathrm{P}_{\mathrm{o}}\right)$

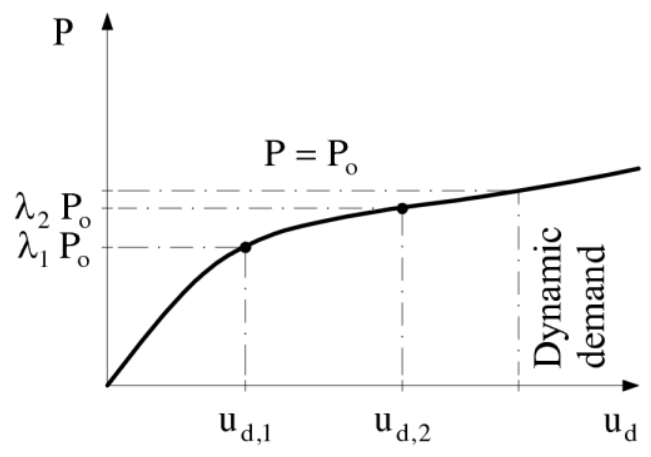

(c) Pseudo-static response

Figure 9. Simplified dynamic assessment and definition of pseudo-static response 


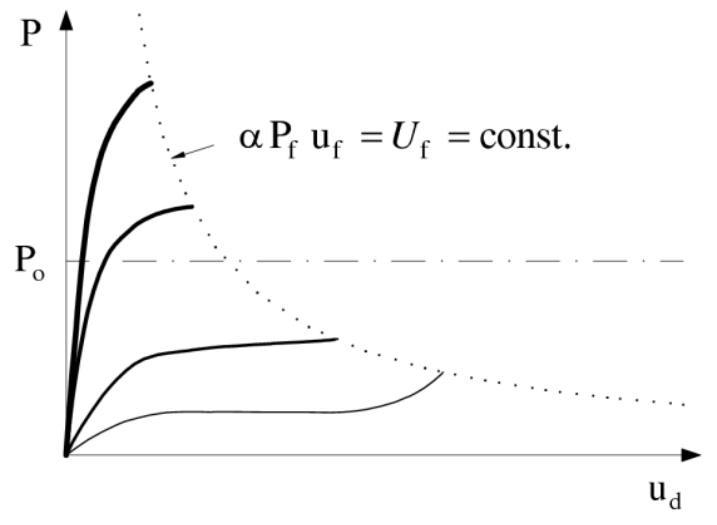

Figure 10. Different pseudo-static responses with identical energy absorption capacity 


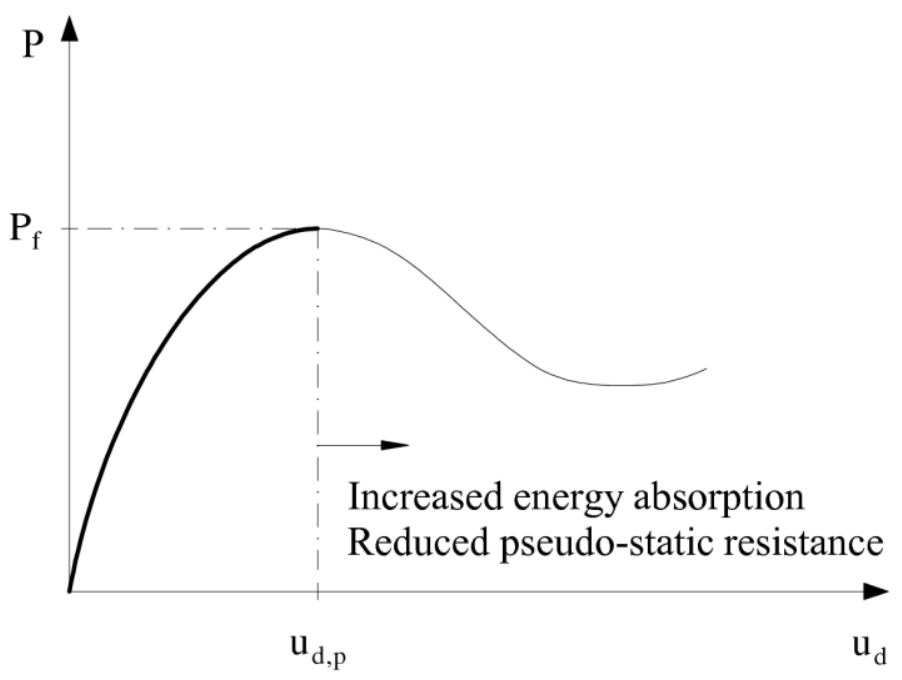

Figure 11. Significance of increased energy absorption capacity 

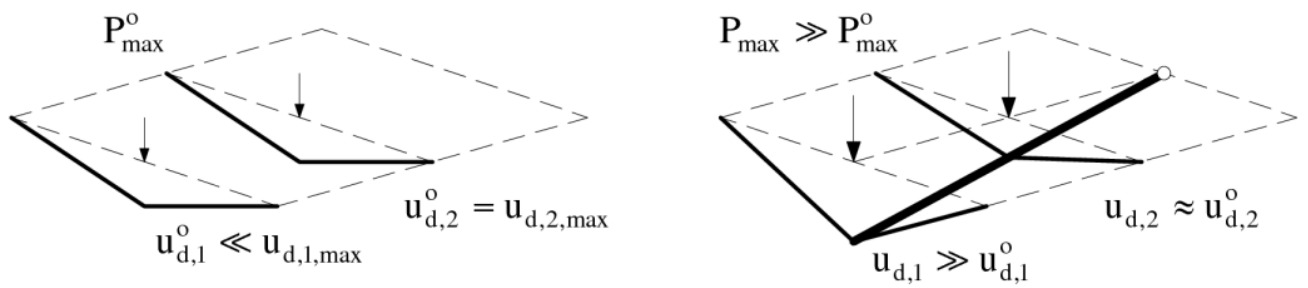

(a) Positive redundancy
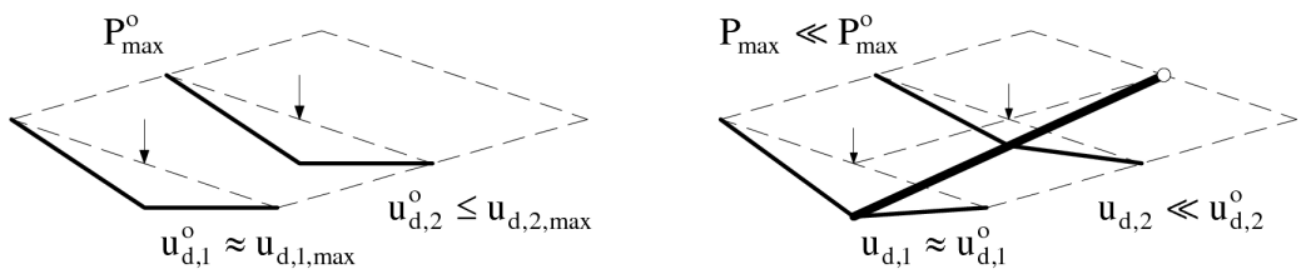

(b) Negative redundancy

Figure 12. Influences of redundancy in progressive collapse assessment 